\section{EGFR inhibition boosts stem cell mobilization}

\section{By Lauren Martz, Staff Writer}

Researchers at the Cincinnati Children's Hospital Medical Center have shown that the epidermal growth factor receptor inhibitor Tarceva erlotinib can increase the mobilization of stem cells from the bone marrow to the blood, which is an important step in stem cell transplants for blood cancers. ${ }^{1}$ The findings could open up new oncology indications for the small molecule, which is marketed by Astellas Pharma Inc. and Roche to treat non-small cell lung cancer and pancreatic cancer based on the antiproliferative effects of blocking the receptor.

Autologous stem cell transplants for cancer involve stimulating the release of hematopoietic stem and progenitor cells (HSPCs) from the bone marrow to the blood, where the cells are harvested and expanded ex vivo. In the meantime, the patient is given chemotherapy to eradicate the blood or bone marrow cancer, after which the HSPCs are reintroduced to repopulate the blood and bone marrow with healthy cells.

The standard strategy to mobilize HSPCs from the marrow involves treatment with G-CSF (CSF3), which is a stem cell growth factor. However, some patients' stem cells do not mobilize in response to G-CSF, either naturally or due to the effects of past chemotherapy, so additional stimulation is needed.

The newest stimulator is Mozobil plerixa-

"Whether or not we
continue to use erlotinib
will depend on the support
of the companies that
own the compound. We
only have a patent on
the mechanism of EGFR
inhibition to enhance
G-CSF-induced stem cell
mobilization."
Cincinnati Children's Hospital
Medical Center

Now, a Cincinnati team led by Hartmut Geiger has identified one such new mechanism: inhibiting epidermal growth factor receptor (EGFR). In a paper published in Nature Medicine, the group showed that inhibiting EGFR significantly increased stem cell mobilization in mice.

Geiger is associate professor in the Division of Experimental Hematology and Cancer Biology at the Cincinnati Children's Hospital Medical Center. The team included researchers from Eastern Kentucky University and the University of Kentucky.

In mice, the group first showed that G-CSF plus epidermal growth factor (EGF) decreased mobilization of stem cells compared with G-CSF alone. Also, transplantation of G-CSF- and EGF-treated marrow into marrow-deficient mice caused fivefold less chimerism and lowered repopulation compared with transplantation of marrow from mice treated only with G-CSF.

The group then transplanted mice with bone marrow from transgenic animals expressing an Egfr mutant that had significantly lower activity. In those animals, G-CSF significantly increased mobilization compared with that in mice given transplants from wild-type animals.

Tarceva also increased mobilization in the mice.

Geiger's team went on to tease out the mechanism by which Tarceva and other EGFR inhibitors exert their mobilization effects. In mice, the group showed that Tarceva lowered levels of active cell division cycle 42 (Cdc42), which is downstream of Egfr and is involved in stem cell stromal adhesion.

In contrast, G-CSF plus EGF increased activity of $\mathrm{Cdc} 42$.

Taken together, the findings suggest that blocking Cdc42 allows for the release of stem cells from the stroma.

\section{Mobilizing for the clinic}

According to Geiger, "mobilization studies in mouse models reflect what you might see in a clinical trial in most cases. The research is very translatable compared with findings from animal cancer models."

He told SciBX the team's next steps are to use a humanized mouse model, "where the human hematopoietic stem cells are transfor (AMD3100), a CXC chemokine receptor 4 (CXCR4; NPY3R) antagonist. It is marketed by Genzyme Corp. to increase mobilization of HSPCs to the bloodstream for collection in combination with G-CSF and subsequent autologous transplantation in patients with lymphoma or multiple myeloma (MM) whose cells mobilize poorly. The drug was approved in 2008.

Nevertheless, said Paul Shaughnessy, medical director of the Adult Blood and Marrow Stem Cell Transplant Program at the Texas Transplant Institute, "there are still failures to mobilize stem cells with combinations of G-CSF and plerixafor, so any new mechanism that may be an adjunct to stem cell mobilization will be an advantage for some patients." planted into mice so they have the human blood system. Then we need to see if erlotinib enhances mobilization in the system. Whether or not we continue to use erlotinib will depend on the support of the companies that own the compound. We only have a patent on the mechanism of EGFR inhibition to enhance G-CSF-induced stem cell

Tarceva clearly is not the only game in town, as there are at least 10 other small molecule EGFR inhibitors in the clinic or on the market.

Niels Jørgen Skartved, principal scientist at Symphogen A/S, thinks that before Geiger's team advances into additional mouse studies, it might be a good idea to run in vitro drug-drug interaction studies. "Erlotinib is metabolized by the cytochrome P450 system. mobilization." 
Cytokines, including G-CSF, have been reported to interfere with cytochrome P450. It should be addressed if G-CSF interfered with the metabolism of erlotinib," he noted.

Symphogen's Sym004, an anti-EGFR antibody, is in Phase I/II testing to treat advanced solid tumors. Michael Kragh, director of antibody pharmacology at Symphogen, told SciBX that anti-EGFR antibodies do not interfere with cytochrome P450.

Kragh also suggested that the known skin rash side effect of EGFR inhibitors could pose a problem. "Risk of infections may be an issue since bone marrow transplant patients are very vulnerable to infections in the period post-transplantation," he said.

Geiger noted that adverse events are dose dependent and that his group's results in mouse models suggest that Tarceva induced stem cell mobilization at a dose that was twofold to threefold lower than the doses used to treat tumors.

"We also shouldn't forget that we treat patients transiently in this indication. The patient takes these drugs for three to four days and then they're done," he said.

\section{Adjunct therapy}

The consensus among researchers contacted by SciBX is that EGFR inhibitors will not replace existing strategies to mobilize stem cells and instead should be considered for their additive benefits.

"The standard of care is G-CSF. You will not replace that, but EGFR inhibitors could be a good addition or good for use in combination in patients that have problems mobilizing hematopoietic stem cells. EGFR inhibitors could probably serve a similar role [to] plerixafor," said Geiger.

He added that combining EGFR inhibitors with Mozobil to enhance the effect of G-CSF could increase potency even further.

Skartved agreed: "If sufficient yield can be obtained by fewer G-CSF injections when followed by erlotinib, this could be a more cost-effective mobilization strategy" than G-CSF alone.

$\mathrm{He}$ also noted that "fewer G-CSF injections may reduce the risk of enlarged or ruptured spleen."

Geiger suggested that EGFR inhibitors could have an advantage over Mozobil because they "seem to act preferentially on stem cells, which are the cells of interest. Mozobil targets both hematopoietic stem and progenitor cells with the same efficacy."

Both Skartved and Shaughnessy wanted to see more studies on the specific types of stem cells mobilized by EGFR inhibitors.

The combination of G-CSF with EGFR inhibitors "is a new mobilization force not fully understood, and may release different sets of HSPCs that may have different capacity for differentiation as compared to existing strategies. Further pharmacological studies may be required to address this," said Skartved.

Shaughnessy said studies also should be done in humans "to find a unique spot for this potential mechanism, such as characterizing the type of stem cells mobilized. It is possible that this mechanism of mobilizing stem cells may just be a small adjunct to already very effective methods. However, if this mechanism results in a more primitive stem cell with homing properties and a less inflammatory or more tolerogenic immune profile, this may be more important and change our current paradigm of mobilizing stem cells."

Geiger told SciBX that the method of inhibiting EGFR to increase stem cell mobilization has been patented and that the IP is available for licensing. He said the Cincinnati team is in the process of securing funding to further pursue translation of the research into the clinic.

Genzyme did not respond to interview requests.

Martz, L. SciBX 3(40); doi:10.1038/scibx.2010.1197

Published online Oct. 14, 2010

\section{REFERENCES}

1. Ryan, M.A. et al. Nat. Med.; published online Sept. 21, 2010; doi:10.1038/nm.2217

Contact: Hartmut Geiger, Cincinnati Children's Hospital Medical Center, Cincinnati, Ohio

e-mail: Hartmut.geiger@cchmc.org

\section{COMPANIES AND INSTITUTIONS MENTIONED}

Astellas Pharma Inc. (Tokyo:4503), Tokyo, Japan

Cincinnati Children's Hospital Medical Center, Cincinnati, Ohio

Eastern Kentucky University, Richmond, Ky.

Genzyme Corp. (NASDAQ:GENZ), Cambridge, Mass.

Roche (SIX:ROG; OTCQX:RHHBY), Basel, Switzerland

Symphogen A/S, Copenhagen, Denmark

Texas Transplant Institute, San Antonio, Texas

University of Kentucky, Lexington, Ky. 